\title{
Viral Pneumonia in Severe Respiratory Failure
}

\author{
Suveer Singh ${ }^{a}$ Pallav L. Shah ${ }^{a, b}$ \\ ${ }^{a}$ Chelsea and Westminster Hospital, NHS Foundation Trust, and ${ }^{\mathrm{b}} \mathrm{NIHR}$ Respiratory Biomedical Research Unit, \\ Royal Brompton and Harefield NHS Foundation Trust, Imperial College, London, UK
}

Acute viral respiratory infections are the most common illnesses experienced by people worldwide. Most notable amongst these are rhinoviruses, influenza (Flu A and $B$ ), adenoviruses, picornaviruses, respiratory syncytial virus, parainfluenza viruses $1-3$, human metapneumovirus, human coronaviruses and the herpesviruses. Their reported frequency ranges from 0 to 7 per annum, and this diminishes with increasing age [1]. At least one such virus is isolated in up to $53 \%$ of patients attending an emergency department with acute respiratory tract infections [2]. Respiratory viruses are usually self-resolving in the immunocompetent host. In those who are immunocompromised as well as in a proportion of otherwise well individuals, however, they can pose potentially lifethreatening consequences. This situation is perhaps best epitomized by the influenza pandemic of 1918 that had a fatality rate of millions [3]. In recent years, the world has experienced equally fearful but less catastrophic pandemics; accurate population data from these have provided insights into risk factors, outcomes and confounding factors. The epidemics of severe acute respiratory syndrome (SARS), swine flu (H1N1) and the so-called Middle East respiratory syndrome have challenged populations and global healthcare systems over the last decade [4-6]. Fortunately, the careful retrospective analysis of their viru-

\section{KARGER}

E-Mail karger@karger.com

www.karger.com/res lence, the susceptibility factors of the affected patient groups, the predictive clinical features and the impact of vaccinations and available pharmaceutical and supportive treatments have provided lessons for preparedness for pandemics in the future [7].

Against this backdrop, we are reminded that, at an individual level, the diagnosis of viral pneumonia with particular reference to the demonstration of viral pathogenicity is difficult. More specifically, in patients with a critical illness and severe respiratory failure not primarily suspected to be due to a virus, the challenges of recognizing viral etiology, diagnostic sampling, testing and treatment of viral pneumonitis remain complex.

The herpesvirus family is a group of viruses (Herpesviridae) characterized by their ability to remain latent within tissues following initial infection and a tendency to reactivate at mucocutaneous sites [8]. The most common forms involved in the respiratory tract are herpes simplex virus (HSV) 1, cytomegalovirus (CMV), Epstein-Barr virus (EBV) and human herpes virus (HHV) 6 and 8.

The prevalence of oropharyngeal HSV1 in healthy adults is $2-3 \%[9,10]$. This is similar to the prevalence in hospitalized non-intensive care unit (ICU) patients [11]. A reactivation of herpesviruses may occur due to local
C 2014 S. Karger AG, Basel

0025-7931/14/0874-0267\$39.50/0
Dr. Suveer Singh

Chelsea and Westminster Hospital, Imperial College 369 Fulham Road

London SW10 9NH (UK)

E-mail suveer.singh@imperial.ac.uk 
trauma (e.g. dental procedures, trigeminal nerve root decompression and intubation leading to the seeding of damaged epithelial cells from disruption of reservoirs in the cervical sympathetic and vagal neuronal ganglia) or systemic immunosuppression that hinders $\mathrm{T}$ cell immunity (e.g. organ or marrow transplantation and HIV infection) $[8,11]$. Following oropharyngeal reactivation, seeding of the virus into the respiratory and gastrointestinal tract can occur and the potential for herpetic tracheobronchitis or pneumonia exists [12]. However, secondary infections in the respiratory and gastrointestinal tract are reported to occur very infrequently in immunocompetent patients, and visceral disease is rare in immunocompetent patients with orofacial herpes.

Key questions for the context of Herpesviridae and severe respiratory failure are whether a detection in the respiratory tract assumes pathological infection or has a bystander effect and also when treatment is indicated. Case series and observational cohort studies over 30 years have informed these questions in critical illness.

Tuxen et al. [13] found characteristic HSV cytoplasmic inclusion bodies in the bronchial epithelial cells of 14/36 (40\%) patients with acute respiratory distress syndrome (ARDS) consecutively sampled by tracheobronchial aspirates. These patients had ventilatory support of increased duration and late mortality.

Retrospective cohort studies on critically ill ventilated patients with HSV1 isolated from bronchoalveolar fluid and confirmed by cultured cell-cytopathic effects suggest that the $40 \%$ chance of mortality was more likely due to underlying disease severity than the HSV infection itself [14]. This implies that HSV1 is merely a marker, perhaps due to the reactivation of endogenous HSV1. To define causality, the true incidence of herpesvirus infections in the respiratory tract of critically ill patient cohorts must first be defined.

In a large prospective study, Bruynseels et al. [11] demonstrated that $22 \%(169 / 764)$ of ICU patients had HSV1positive throat swabs; $31 \%$ had HSV1 in the lower respiratory tract compared with $5 \%$ who were oropharyngeal HSV1 negative. Overall, the virus was isolated in the lower respiratory tract of $16 \%(58 / 361)$. Six percent had ARDS; HSV in the throat was found in 43\% (20/46) and in the lower respiratory tract in $21 \%$. Causality could not be addressed, as ARDS preceded sampling.

Thus, the presence of HSV in the throat is a highly significant and independent risk factor for the development of lower respiratory tract infections with HSV in critically ill patients [11]. ICU length of stay increases the likelihood of HSV detection. However, multiple regression analysis has not shown the presence of HSV to be an independent indicator of mortality [11].

Critically ill patients at risk of HSV1 detection in the respiratory tract include the elderly as well as patients with associated sepsis or who have recently received glucocorticoid treatment [15]. This particular retrospective study on 48 cases of HSV1 utilized a validated qualitative polymerase chain reaction (PCR) for the identification of HSV from respiratory secretions.

In this issue of Respiration, Tachikawa et al. [16] report the use of rapid screening qualitative PCR for identifying herpes viral DNA in respiratory samples from 87 patients with acute lung injury or ARDS, followed by quantitative PCR of the viral load from the samples where Herpesviridae was detected. This was a mixed group of patients with respiratory failure, approximately $56 \%$ of whom were immunocompromised due to chronic steroid use or acquired immunodeficiency; $31 \%$ were intubated. The patients were stratified according to a priori criteria for the likelihood of clinical (proven, probable or possible) viral pneumonia.

Certain statements were possible regarding the PCR detection of Herpesviridae in this cohort of ARDS. First, herpesviruses were present in $40 \%$ of the patients, with $16 \%$ having multiple viruses. The individual prevalences were HSV 1 in $13 \%$, EBV in $18 \%$ and CMV in $24 \%$. Second, the detection of HSV1 was more prevalent with intubation but not influenced by the immune status of the patient. By contrast, CMV and EBV were unaffected by intubation, significantly so in immunocompromised patients. Third, none of the bronchoalveolar fluid levels correlated with blood markers of viremia, reiterating the importance of site-specific sampling. Finally, Tachikawa et al. provide a putative diagnostic threshold viral load for CMV in bronchoalveolar fluid with $87.5 \%$ sensitivity and $84.6 \%$ specificity, for likely or probable viral pneumonia [16].

The presence of the virus can now be demonstrated quickly through qualitative PCR and viral load measured by quantitative PCR [16]. The mortality risks associated with Herpesviridae infection of the respiratory tract in immunosuppressed patients are also well established [10]. Safe prophylactic treatment of HSV1 has also been demonstrated in immunocompetent patients with ARDS who are at risk of acquiring HSV1 infection [17]. What has not yet been convincingly addressed is the establishing of the presence of viruses (by PCR), their viral load and their functional cytopathic effects (i.e. not just the presence of intracytoplasmic inclusion, but via cell culture techniques, which can take days). The development 
of such a rapid functional test of cytopathic effect in lower respiratory tract samples, combined with quantitative viral load, would afford scrutiny of the estimated clinical burden of these viruses in the respiratory tract of mechanically ventilated patients. Randomized prospective studies of this combined quantitative/functional strategy could enable a meaningful interpretation of the effects of antiviral treatments in this at-risk group. Until such time, guidance on diagnosis and treatment will be subject to risk stratification. Qualitative PCR for oropharyngeal swab identification of herpesviruses will detect those at risk of clinically important infection. Qualitative and quantitative PCR of the lower respiratory tract will further stratify those who warrant empirical treatment. Subsequent sampling and analysis may then be necessary in those mechanically ventilated patients who do not respond to usual supportive and anti-infective (i.e. bacterial and fungal) treatment or those who are immunocompromised.

With improved access to rapid DNA and RNA identification assays, precedence from the work in the fields of HIV and viral hepatitides and the available clinicopathological characterization, there is now an opportunity to develop clinical decision algorithms for the management of respiratory-tract herpesviruses in severe respiratory failure. This may guide the design of future prospective randomized trials to establish the diagnostic accuracy of $\mathrm{PCR} /$ functional assays for herpesvirus infection in severe respiratory failure.

\section{References}

1 Monto AS: Epidemiology of viral respiratory infections. Am J Med 2002;112(suppl 6A): $4 \mathrm{~S}-12 \mathrm{~S}$.

- 2 Yu X, Lu R, Wang Z, Zhu N, Wang W, et al: Etiology and clinical characterization of respiratory virus infections in adult patients attending an emergency department in Beijing. PLoS One 2012;7:e32174.

-3 Cunha BA: Influenza: historical aspects of epidemics and pandemics. Infect Dis Clin North Am 2004;18:141-155.

4 Pearson H, Clarke T, Abbott A, Knight J, Cyranoski D: SARS: what have we learned? Nature 2003;424:121-126.

-5 Fisher D, Hui DS, Gao Z, Lee C, Oh MD, Cao B, Hien TT, Patlovich K, Farrar J: Pandemic response lessons from influenza H1N1 2009 in Asia. Respirology 2011;16:876-882.

-6 Assiri A, Al-Tawfiq JA, Al-Rabeeah AA, AlRabiah FA, Al-Hajjar S, Al-Barrak A, Flemban $\mathrm{H}, \mathrm{Al}-\mathrm{Nassir} \mathrm{WN}$, Balkhy $\mathrm{HH}, \mathrm{Al}-$ Hakeem RF, Makhdoom HQ, Zumla AI, Memish ZA: Epidemiological, demographic, and clinical characteristics of 47 cases of Middle East respiratory syndrome coronavirus disease from Saudi Arabia: a descriptive study. Lancet Infect Dis 2013;13:752-761.

7 Berera D, Zambon M: Antivirals in the 2009 pandemic - lessons and implications for future strategies. Influenza Other Respir Viruses 2013;7(suppl 3):72-79.
8 Corey L: Herpes simplex virus; in Mandell, Bennett and Dolin (eds): Principles and Practice of Infectious Diseases, ed 6. Philadelphia, Churchill Livingstone, 2005, pp 1762-1780.

-9 McMillan JA, Weiner LB, Higgins AM, Lamparella VJ: Pharyngitis associated with herpes simplex virus in college students. Pediatr Infect Dis J 1993;12:280-284.

10 Ramsey PG, Fife KH, Hackman RC, Meyers JD, Corey L: Herpes simplex virus pneumonia; clinical virologic and pathologic features in 20 patients. Ann Intern Med 1982;97:813820.

11 Bruynseels P, Jorens PG, Demey HE, Goossens H, Pattyn SR, Elseviers MM, Weyler J, Bossaert LL, Mentens Y, Ieven M: Herpes simplex virus in the respiratory tract of critical care patients: a prospective study. Lancet 2003;362:1536-1541.

12 Engelmann I, Gottlieb J, Meier A, Sohr D, Ruhparwar A, Henke-Gendo C, Gastmeier P, Welte T, Schulz TF, Mattner F: Clinical relevance of and risk factors for HSV-related tracheobronchitis or pneumonia: results of an outbreak investigation. Crit Care 2007;11: R119.
13 Tuxen DV, Cade JF, McDonald MI, Buchanan MR, Clark RJ, Pain MC: Herpes simplex virus from the lower respiratory tract in adult respiratory distress syndrome. Am Rev Respir Dis 1982;126:416-419.

14 van den Brink JW, Simoons-Smit AM, Beishuizen A, Girbes AR, Strack van Schijndel RJ, Groeneveld AB: Respiratory herpes simplex virus type 1 infection/colonisation in the critically ill: marker or mediator? J Clin Virol 2004;30:68-72.

-15 Sundar KM, Ludwig KA, Alward WT, Pearce MJ, Bishop CT, Hammond RC, Hillyard DR, Freestone SW, Ozment A, Cahill BC: Clinical course and spectrum of intensive care unit patients reactivating herpes simplex-1 virus: a retrospective analysis. Indian J Crit Care Med 2008; $12: 145-152$.

16 Tachikawa R, Tomii K, Seo R, Nagata K, Otsuka K, Nakagawa A, Otsuka K, Hashimoto H, Watanabe K, Shimizu N: Detection of herpes viruses by multiplex and real-time polymerase chain reaction in bronchoalveolar lavage fluid of patients with acute lung injury or acute respiratory distress syndrome. Respiration 2014;87:279-286.

17 Tuxen DV, Wilson JW, Cade JF: Prevention of lower respiratory herpes simplex virus infection with acyclovir in patients with the adult respiratory distress syndrome. Am Rev Respir Dis 1987;136:402-405.
Viral Pneumonia in Severe

Respiratory Failure 